\title{
Tamarind (Tamarindus indica linn.) and Sweet Sorghum (Sorghum bicolor L.Moench): their Potential Utilization in Phytotherapy
}

\author{
Regina D. Loria, Norman G. De Jesus, Filomena K. Reyes, and Honorio M. Soriano Jr \\ \# Pampanga State Agricultural University, Magalang, Pampanga, 2011, Philippines \\ E-mail: loria.regina@yahoo.com
}

\begin{abstract}
The use of botanical extracts and essential oil in skin care has been increasing due to greater demand on the part of consumers to use natural ingredients. Tamarind and Sweet Sorghum really have big potentials for reaching the public and showcasing its benefits, thus this study could encourage growers to raise more Tamarind and Sweet Sorghum in their areas not only as food but as a raw material in the production of natural products which are for health and wellness. Both Tamarind and Sweet Sorghum possess skin healing effect which maybe attributed to their biologically active components. Tamarind possess to have bioflavonoids and alkaloids which occur in its leaves, pulp and bark. The bark contains tannin which are recommended for treatments of inflammation, ulceration and skin disease. Tamarind has Tartaric acid that makes it possible for tamarind to works wonders on oily skin with pimples and on sun-damaged. Sweet Sorghum on the other hand contains emulsin, a substance that can give a moisturizing effect on the skin. The majestic phytochemistry of Tamarind and Sweet Sorghum encouraged the researcher to produce and test the acceptability, efficacy and safety of different skin care products that are commonly needed by the community. The Tamarind Leaves soap was proven to be highly acceptable in terms of its color, odor, texture, hardness and over-all appearance. Both the Tamarind soap and the Sweet Sorghum soap were safe and free from insoluble soap and fatty acid soap. The percent reduction of acne in using Tamarind soap, Sweet Sorghum and Commercial soap have similar effect on the tenth and twelve days of use. The initial means of the treatments ranges from 10.00 pustule to 2.00 pustule. After 12 days of treatment the mean decrease is zero or equivalent to $100 \%$ decrease in the number of acne. The result of this study maybe explained with the result on antibacterial property test (against Staphylococcus A.) of Tamarind soap and Sweet Sorghum Soap. Tamarind soap with 8\% extract was found to be most effective in reduction of pimples. The Tamarind shower gel and Sweet Sorghum shower gels were effective against Staphylococcus Aurous. Tamarind Bark Ointment was an effective anti - inflammatory agent particularly on swelling and redness as well as for wound healing. Tamarind scrub salt, shower gel and liniment were also highly acceptable and found to be safe and effective. Result on the acceptability of Sweet Sorghum natural products are comparable to the acceptability of Tamarind natural products. The development of technology for the Production of Natural Products from Tamarind and Sweet Sorghum is timely, considering the growing consciousness of consumers on safe, organic and healthy natural products. Likewise, this product diversification scheme can promote multi-uses and competitive of the Tamarind and Sweet Sorghum.
\end{abstract}

Keywords - Tamarind; Sweet Sorghum; Potential Utilization; Phytotherapy

\section{INTRODUCTION}

Nowadays, the trend is switching life back to botanicals. People are now more interested with using botanical products for daily living. Tamarind natural products have big potentials to the public and showcasing its benefits, thus this study can encourage man to produce tamarind in their areas not only as a food but as a raw material in the production of natural healing products which are for health and wellness.

All parts of the tamarind tree are useful and the value of the many traditional uses of tamarind have been confirmed, in particular the Antioxidant activity of the seed coat extract,
Anti-inflammatory activity and Antimicrobial Activity. Despite the diverse use of Tamarind, only few Tamarind products are produced locally and the most popular Tamarind product is the sinigang mix. According to Lanhers et.al as stated by Rummel [1], the decorticated tamarind kernels contain a gel-forming substance and have been found superior in the manufacture and stabilization of cosmetic gels and emulsions. Tamarind has also been used as an exfoliating agent which is due to the Tartaric acid found in the tamarind pulp. Tamarind fruit and seeds have been confirmed to possess Antibacterial and Antifungal properties, and the tamarind kernel contains $4.5-6.5 \%$ semidrying oil. These makes it possible for tamarind to works wonders on oily skin with pimples and on sun-damaged, dry 
skin with wrinkles. Thus giving tamarind the value in the preparation of skin and hair products.

Tamarind pulp is used in other countries to as a laxative and refregerant. The pulp is applied on inflammations, as a gargle for sore throat, and mixed with salt as a liniment for rheumatism. The pulp is said to aid the restoration of sensation in cases of paralysis. The tamarind leaves and flowers, dried or boiled are used as poultices for swollen joints, sprains and boils.Its extracts are as antiseptics and febrifuge. They are also used to treat conjunctivitis, dysentery, jaundice, erysipelas and hemorrhoids. The bark of the tree is regarded as an effective astringent. A decoction is used in cases of gingivitis, asthma, and eye inflammations. Lotion and poultice made from the bark are applied on open sores and caterpillar rashes. The powdered seed are made into paste for drawing boils. The seed coat also serves as astringent. The infusion of the roots is used as an ingredient in prescription of leprosy (http://www.hort.purdue.edu/ newcrop/ morton/tamarind.html).

Sweet Sorghum on the otherhand is also an important commodity of the institution known for its biofuel use and as an alternative food and feed. But little is known about its majestic effect which promotes moisturizing and softening effect. The plant contains glucoside, dhurin, emulsin and sorgin. Emulsin is a substance that can give a moisturizing effect on the skin. Sweet Sorghum syrup is comparable in its use and properties with Honey and Molasses. It contains substances which are found in Honey and Molasses but has higher mineral and micronutrient content. Hence, this study was conducted to develop, formulate and produce natural products from Tamarind and Sweet Sorghum as well as to determine the efficacy, safety and acceptability of the products. The results of the study would prove prospective consumers, farmers, growers and researchers from the Agroecological zone with information that could serve as a reference for the production of cosmetic products and skin treatment materials which contains Tamarind extracts and Sweet Sorghum.

Research Objectives, The general objective of the study was to formulate and evaluate the efficacy, safety and acceptability of natural products from Tamarind and Sweet Sorghum. Specifically, this study aimed to determined the following specific objectives: (1) to profile the physico, chemical and antimicrobial characteristics of Tamarind Soap and Sweet Sorghum Soap; (2) to determine the antiacne and wound healing potential of Tamarind soap and Sweet Sorghum Soap in terms of their effects on pimples, wounds and over-all skin condition; (3) to determine the significant differences on the anti - inflammatory effect of the sweet tamarind ointment treatments on the inflamed hind paws of rabbits in terms of : Swelling, Redness and Wounds; (4) to characterize Tamarind and Sweet Sorghum shower gels , spa salts and liniment in terms of : Efficacy and Safety; (5) determine the economic potential of developed natural products from Tamarind and Sweet Sorghum.

\section{MATERIAL AND METHODS}

Conceptual Framework, To prove the development of Natural Products Tamarind and Sweet Sorghum, the researcher determined the ethno medicinal uses, pharmacologic uses and components or phytochemicals of the different plant parts of Tamarind and Sweet Sorghum. This was followed by the determination of the methods of preparing the extracts to be used in product development. Different procedures in producing organic health products (soap, ointment, shower gel, liniment and spa salt) were compared and were modified to suit the nature of the plant to its utilization.Pilot testing was used in the development of the products. Initial products were evaluated for acceptability, results in the pilot testing were used as basis in the improvement of the products.

The developed and improved products were evaluated for acceptability by the product development enthusiast. Chemical characterization of the products includes the test for safety which was performed in the laboratory. The antimicrobial characterization of the soap and shower gel includes the test for the Antibacterial potential of the soap and shower gel against Staphylococcus Aurous. The evaluation of the effects of products was done by distributing samples of the products to possible users. Questionnaires were given to the respondents to evaluate the effectiveness of the products. To test the products for their possible marketability, products were presented in exhibits. The cost analysis was done in consultation with the experts.

Materials and Methods, This portion contains all the necessary procedures undertaken by the researcher for the progress and achievement of objectives of this study. This research made use of the descriptive - experimental method of research to answer the objectives of the study. Complete Randomized Design was used in the study.

\section{A. To test the physico chemical properties of the Tamarind soap and Sweet Sorghum Soap}

For the physical properties of the treatments, the following will data will be gathered:

- Mean of the sensory attribute in terms of texture.

- Mean of the sensory attribute in terms of color.

- Mean of the sensory attribute in terms of odor.

- Mean of the sensory attribute in terms of hardness.

- Mean of the sensory attribute in terms of appearance.

- Mean of the sensory attribute in terms of effectiveness and over-all acceptability.

- Grand mean.

The subjects for the physical property test were healthy volunteers aged 14-40. Each of the subjects will receive a product (control soap ,soaps with pulp, bark, roots, and leaves extract) made identical in packaging.

Eighteen samples per treatment had been tested for chemical properties in the laboratory.

This series of tests utilized common laboratory chemicals and methods for determining certain chemical properties of the tamarind soap treatments.

- Test for free alkali. This test involved the use of phenolphthalein to react with the soap dissolved in water

- Test for insoluble soaps. In this test, three test tubes per treatment of soap solution were made to react with calcium chloride, magnesium chloride and ferric chloride. 
- Fatty acids from soaps. This test made use of diluted sulfuric acid, carbon tetrachloride and bromine to determine if the soap is saturated with fats.

- Soap's reactions on litmus paper/ acidity tests. Honey is added as an additional ingredient in the preparation of Tamarind soap to improve its moisturizing effect. The inclusion of Honey was a solution to the recommendation of the respondents that the soap has low moisturizing effect

\section{B. To test the antibacterial property of Tamarind Soap and Sweet Sorghum Soap, the following procedures were undertaken:}

Preparation of Tamarind Soap and Sweet Sorghum Samples for Antibacterial Test.

Get 5 grams of scrape soap. Dissolve it in 175-190 ml of warm water. Place the mixture in a clean dry container then cover. Do the same with the Commercial Herbal Soap.. Samples were brought to the IVMZ Microbiology Lab. for Analysis.

Antibacterial Test, The study used the streaking method, a method that uses only a portion of a bacteria specimen which is placed on the surface of an Agar solution and Streaked or spread over the surface by mean of a transfer loop. Sterilized filter paper disc were used to hold the soap samples to be tested in the study. Individual disc were immersed into the different soap samples for five minutes. This was done to ensure that the filter paper disc were saturated with the soap samples and were placed aseptically on the surface of the inoculated plates using forceps. The disc were pressed gently to prevent from falling off during incubation. The plates were incubated at $37{ }^{\circ} \mathrm{C}$ overnight.

Relative susceptibility by the organism to test antibacterial solution were demonstrated by clear zones of inhibition and measured with the use of a transparent ruler in millimeters. Mean measurement of the three replicates per treatment was then obtained.

\section{To test the anti-acne potential the Tamarind soap and Sweet Sorghum Soap}

In the study, anti-acne effects soap on acne, 40 individuals were given tamarind leaves decoction based soap, 40 individuals were given Tamarind extract base soap, another 40 individuals were given Commercial anti-acne soap and another 40 individuals were given Sweet Sorghum soap. The respondents assessed the number of acne, relative size and color of acne and the over-all effect of the soap on the acne and on the face. The respondents were given one month to use and observe the effect of the soap on their acne. The respondents were instructed to use the soap twice a day to prevent irritation. They were also instructed to evaluate the effect of the soap on the number of their acne, size of their acne, color improvement of the skin having the inflammation whether there is the reduction of redness or other color associated to acne and the over-all effect of the soap on the acne.

Presence of pimples was gathered through interview and questionnaire. Results are observed every 2 days until the pimples are gone. Different concentration of Tamarind soap were also tested following the same procedure in the test for efficacy of the Tamarind soap. To test the wound healing property of the Tamarind Leaves Decoction based soap and Sweet Sorghum Soap.

\section{To test the wound healing effect of Tamarind Soap and Sweet Sorghum Soap}

The respondents were given one week to use and observe the effect of the soap on their wounds. The respondents were instructed to use the soap twice a day to prevent irritation. They were instructed to evaluate the effect of the soap such as the skin color and lesions.

\section{E. To test the anti-inflammatory potential of the Tamarind ointment}

Induction of Inflammation, Oil of wintergreen $(0.1 \mathrm{ml})$ was injected into the dorsal plantar surface of the hind paws of nine (9) male rabbits. After one (1) hour, the initial measurement of redness and swelling were measured in the hind paws of the experimental animals. Swelling measurement was done using thread to get the circumference of the hind paws. The length measurement of the thread was then measured using a ruler in millimeters. Redness was compared against a red felt paper to determine the intensity of the color of the inflammation.

Application of Treatments, Application of treatments was done with a total of three (3) trials. Three replicates were required for every treatment. The right and left hind paws with methyl-salicylate induced inflammation were used in the application of treatment. Measurement of the disappearance of redness and swelling was done at one (1) hour interval. After the first trial and the inflammation was allowed to subside. Twenty-four to seventy-two hours after the settlement, trials were repeated until the third time using the same paw.

\section{F. To measure the wound healing property of Tamarind Bark Ointment}

The following procedures were undertaken: The experimental animals were anaestisized by putting a cotton ball thoroughly wet with Chloroform. Mice were kept inside the bottle for $10-15 \mathrm{sec}$ and were removed as soon as they became in active and unconscious. By using sterilized iris scissors a square shaped cutaneous wound approximately $1 \mathrm{~cm} \times 1 \mathrm{~cm}$ and extending to the fascid covering the back muscle lumbar were done on each mice.

Application of Treatment, All wounds were treated with ointment approximately $0.2 \mathrm{ml}$ for 7 days. The administration of the cream was twice in a day or once in every in every 12 hours. The ointment was applied liberally until it covered the whole wound. Each wound was measured in $\mathrm{cm}$ using ruler right before the next application of treatment. The time it took the wound to covered by connective tissue matrix was also determined.

During the wound healing process, supplementary observations were done. Dermatological changes such as skin color and lesions were noted.

\section{G. To evaluate the Tamarind Spa Salt and Sweet Sorghum Spa Salt}

The researcher made use of 15 individuals to give their response as to the product's listed characteristics. The following data will be collected after the application of the 
spa salt to the skin: (1) Odor; (2) Texture; (3) Color; (4) Solubility in Oil; (5) Solubility in Water; (6) pH level; (7) Effectiveness (Skin Smoothening property); (8) Relaxing effect.

These data will be subject to statistical analysis to determine the effect of the treatments used.

\section{H. To evaluate the Tamarind Shower Gel and Sweet Sorghum Shower Gel}

Test for Physical Properties, for the physical properties of the treatments, the following data were gathered:

- Mean of the sensory attribute in terms of color.

- Mean of the sensory attribute in terms of odor.

- Mean of the sensory attribute in terms of texture.

- Mean of the sensory attribute in terms of viscosity.

- Mean of the sensory attribute in terms of appearance.

- Mean of the sensory attribute in terms of effectiveness(ability to smoothen skin)

- Grand mean.

The subjects for the physical property test were healthy volunteers aged 14-40. Each of the subjects received a product (commercial shower gel, tamarind shower gel and sweet sorghum shower gel) made identical in packaging.

Eighteen saples per treatment had been tested for chemical properties in the laboratory.

Test for Chemical Properties, this series of tests utilized common laboratory chemicals and methods for determining certain chemical properties of the Tamarind and Sweet Sorghum Shower Gel as compared with the commercial.

- Test for free alkali. This test involved the use of phenolphthalein to react with the shower gel

- Acidity and Alkalinity test. Reactions on $\mathrm{pH}$ paper

\section{To evaluate the Tamarind Liniment and Sweet Sorghum Liniment}

The researcher made use of 20 individual users of liniments and experts to give their response as to the product's listed characteristics.

The following data will be collected after the application of the liniment to the skin: (1) Color; (2) Odor; (3) Texture; (4) Consistency/ viscosity; (5) Appearance; (6) Efficacy/ Relaxing Effect

\section{J. Production of Selected Natural Products from Tamarind and Sweet Sorghum}

Expected initial income was calculated based on the gross income minus the cost of production.

\section{RESULTS AND DISCUSSION}

\section{A. Physical-Chemical and Antimicrobial Potential of Tamarind Soap and Sweet Sorghum Soap}

The table 1 shows that the Tamarind Leaves Soap is the most preferred Tamarind Soap in terms on appearance and overall acceptability. Sweet sorghum soap on the other hand obtained comparable properties with the Tamarind soap but has the mean in terms of its moisturizing effect. Results indicates that the soap are safe to use as based on the test for their chemical properties. Both the Tamarind Soap and the Sweet Sorghum Soap possesses Antibacterial Potential particularly against Staphylococcus aurous. The results maybe compared to the findings of Pineda that Tamarind has antibacterial potential. The antibacterial potential of Tamarind and Sweet Sorghum maybe attributed to their phytochemicals.

TABLE I

Physical - Chemical and Antimicrobial Potential of TAMARind SoAP AND SweEt SORghum SoaP

\begin{tabular}{|c|c|c|c|c|c|c|c|c|c|c|c|c|c|c|}
\hline & $\frac{\overline{0}}{0}$ & $\frac{\overline{0}}{0}$ & 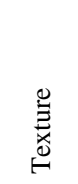 & 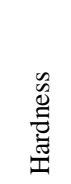 & 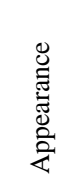 & 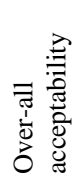 & 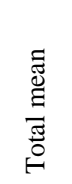 & 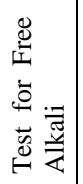 & 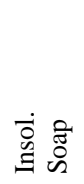 & 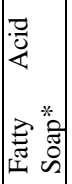 & $\stackrel{\dot{g}}{\stackrel{\Xi}{\Xi}}$ & $\begin{array}{l}\stackrel{\Xi}{\Xi} \\
\text { Z }\end{array}$ & 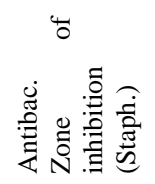 & 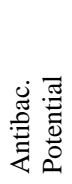 \\
\hline $\mathrm{T}+$ & 3.00 & 3.33 & 3.00 & 3.33 & 3.33 & 3.00 & 3.17 & - & - & - & 8 & Alkaline & $0 \mathrm{~mm}$ & - \\
\hline $\mathrm{T} 1$ & 3.33 & 3.67 & 3.33 & 4.00 & 3.00 & 3.00 & 3.39 & - & - & - & 8 & Alkaline & $2.00 \mathrm{~mm}$ & + \\
\hline $\mathrm{T} 2$ & 3.00 & 3.00 & 3.33 & 3.33 & 3.67 & 3.67 & 3.33 & - & - & - & 8 & Alkaline & $2.00 \mathrm{~mm}$ & + \\
\hline T3 & 3.33 & 2.33 & 3.67 & 4.00 & 4.00 & 3.33 & 3.44 & - & - & - & 8 & Alkaline & $2.00 \mathrm{~mm}$ & + \\
\hline T4 & 3.33 & 3.33 & 4.00 & 4.00 & 3.33 & 3.33 & 3.55 & - & - & - & 8 & Alkaline & $2.00 \mathrm{~mm}$ & + \\
\hline $\mathrm{T5}$ & 3.33 & 3.33 & 3.67 & 3.33 & 3.33 & 3.33 & 3.33 & - & - & - & 8 & Alkaline & 1.89 & + \\
\hline
\end{tabular}

\section{B. Percent Reduction on the Number of Acne as Affected by Different Concentration of Tamarind Extract at Different Time Interval}

Table 2 shows the percent decrease in the number of acne as affected by the concentration of Tamarind leaves at different time interval. Results indicates that $8 \%$ Tamarind leaves show $100 \%$ decrease in the number of acne at the $10^{\text {th }}$ day of treatment. Results shows no significant difference with the Commercial Herbal soap which obtain $97.71 \%$ decrease at the $10^{\text {th }}$ day and the $6 \%$ Tamarind soap obtained $96.95 \%$ on the same day. Results in all of the treatment showed no differences on the $12^{\text {th }}$ day of treatment. This indicates that the Tamarind Leaves Soap is an effective antiacne soap regardless of the concentration of the Tamarind Leaves in the Soap. The result maybe attributed to the phytochemicals of Tamarind and its Antibacterial Potentials. 
TABLE II

PERCENT REDUCTION ON THE NUMBER OF ACNE AS AFFECTED By DIFFERENT CONCENTRATION OF TAMARIND EXTRACT AT DIFFERENT TIME INTERVAL

\begin{tabular}{|c|c|c|c|c|c|c|}
\hline \multirow{2}{*}{ Treatments } & \multicolumn{5}{|c|}{ Days } \\
\hline & 2nd & 4th & 6th & 8th & 10th & 12th \\
\hline $\mathrm{T} 1$ & $84.34 \%$ & $86.98 \%$ & $90.70 \%$ & $93.25 \%$ & $94.25 \%$ & $100 \%$ \\
\hline $\mathrm{T} 2$ & $85.14 \%$ & $87.95 \%$ & $91.45 \%$ & $92.18 \%$ & $96.95 \%$ & $100 \%$ \\
\hline $\mathrm{T} 3$ & $84.15 \%$ & $89.43 \%$ & $93.43 \%$ & $96.48 \%$ & $100 \%$ & $100 \%$ \\
\hline $\mathrm{T}+$ & $85.20 \%$ & $89.44 \%$ & $90.72 \%$ & $95.21 \%$ & $97.71 \%$ & $100 \%$ \\
\hline
\end{tabular}

T1 - $4 \%$ Tamarind Leaves Soap

$\mathrm{T} 2-6 \%$ Tamarind Leaves Soap

T3 - 8\% Tamarind Leaves Soap

T+ - Commercial Herbal Soap

C. Gross Morphological Changes of Skin as Affected by the Anti-Acne Potential of Tamarind Soap

Table 3 presents the gross morphological changes of skin as affected by the different concentration of Tamarind Leaves Soap on the size of the acne, color of the skin and moisturizing effect as perceived by the respondents. Results indicates that the different concentration of Tamarind Leaves Soap showed no significant differences as to its effect on the size of the acne, color of the skin and moisturizing effect .

TABLE III

Gross Morphological CHANGES of Skin AS AFFECTED By ANTI- ACNE POTENTIAL OF TAMARIND SOAP

\begin{tabular}{|c|c|c|c|}
\hline Acne & $\begin{array}{c}\text { Decrease } \\
\text { in Size }\end{array}$ & $\begin{array}{c}\text { Color of } \\
\text { Skin }\end{array}$ & $\begin{array}{c}\text { Moisturizing } \\
\text { Effect }\end{array}$ \\
\hline Treatment + & 3.30 & 3.20 & 3.30 \\
\hline Treatment 1 & 3.30 & 3.20 & 3.20 \\
\hline Treatment 2 & 3.20 & 3.40 & 3.40 \\
\hline Treatment 3 & 3.30 & 3.60 & 3.40 \\
\hline
\end{tabular}

Parameters :
1 - Not effective
3 - Effective
2 - Slightly effective
4 - Very effective

\section{Percent Wound Closur e as Affected by the use of} decoction based tamarind leaves soap and sweet sorghum juggery based soap

Table 4 shows the percent wound closure as affected by the use of Tamarind decoction based soap and Sweet sorghum juggery based soap compared with the commercial soap. Results indicates that the three treatments are comparable in the wound closure effect within the 5 days treatment. However Tamarind soap shows fastest effect. Results in this experiment maybe compared with the antibacterial potential of Tamarind and Sweet Sorghum Soap.
TABLE IV

PERCENT Wound Closure AS AFFeCTED By THE USE OF DECOCTION BASED TAMARIND LEAVES SOAP AND SWEET SORGHUM JUGGERY BASED SOAP

\begin{tabular}{|c|c|c|c|c|c|}
\hline Treatments & \multicolumn{5}{|c|}{ Days } \\
\hline & 0 & 2nd & 3rd & 4th & 5th \\
\hline T+( Commercial) & $0 \%$ & $86.35 \%$ & $90.15 \%$ & $96.56 \%$ & $98.5 \%$ \\
\hline T1( Tamarind) & $0 \%$ & $87.58 \%$ & $93.14 \%$ & $98.15 \%$ & $100 \%$ \\
\hline T2( Sorghum) & $0 \%$ & $86.70 \%$ & $90.76 \%$ & $96.00 \%$ & $97.4 \%$ \\
\hline
\end{tabular}

\section{E. Effect of the Treatments in Reducing the Inflammation} (Redness) on the Inflamed Hind Paws of Rabbits

The initial redness intensity of sweet tamarind leaves based ointment was normal redness. After the injection of the irritant, the redness intensity increases. From the first hour of observation up to the sixth hour, the redness on the inflamed hind paws of rabbits was slight redness. There is no change of redness intensity based on the perception of the evaluators. Sweet tamarind pulp based ointment on the other hand has an initial redness of slight. The first hour and the second hour of observation the redness intensity of the paws increased to medium redness because of the wintergreen oil. The reduction of redness starts during the third hour, the redness intensity becomes slight and this lasts until the sixth hour. Sweet tamarind bark based ointment shows to have an increase in redness from normal to medium redness from the first hour until the third hour of observation. At the fourth hour, the redness starts to reduce into slight redness until the sixth hour. Vandol ${ }^{\mathrm{TM}}$ ointment has an initial redness of slight. At the first hour until the fifth hour the slight redness continues the reduction of redness starts during the sixth hour of observation, wherein the treatment achieved its normal redness. Petroleum jelly has an initial redness of slight and starts at the first and second hour of observation with medium redness and achieved its slight redness at the third hour of observation until the sixth hour. These results were gathered based on the perceptions of the evaluators on the intensity of redness they have seen on the images. Analysis of Variance and Repeated Measure which revealed that the treatments, time and the interaction showed no significant difference. This means that the perceptions of the evaluators in rating the intensity of redness are all the same.

TABLE V

PERCENT REDUCTION OF INFLAMMATION (SWELLING) ON THE INFLAMED HiND PAwS OF RABBits of ALL THE TRIALS

\begin{tabular}{|c|c|c|c|c|c|c|c|}
\hline Treatments & 0 & 1st & 2nd & 3rd & 4th & 5th & 6th \\
\hline Leaves & 100 & 91.87 & 94.35 & 95.42 & 97.89 & 100.00 & 100.00 \\
\hline Pulp & 100 & 89.76 & 92.13 & 95.00 & 97.08 & 100.00 & 100.00 \\
\hline Bark & 100 & 93.70 & 95.46 & 97.95 & 99.54 & 100.00 & 100.00 \\
\hline Vandol $^{\mathrm{TM}}$ & 100 & 87.06 & 90.67 & 93.68 & 96.92 & 99.64 & 100.00 \\
\hline Petroleum & 100 & 89.72 & 91.58 & 95.32 & 97.42 & 99.73 & 100.00 \\
\hline
\end{tabular}

*mean of the same letter shows to have no significant difference at $5 \%$ level of significance (LSD) 


\section{F. Redness Rating of the Inflamed Hind Paws of Rabbits Treated with Different Tamarind Extract based Ointment}

Results showed that treatments showed no significant difference throughout the trials. The prepared ointments are effective and are comparable with the positive controls in reducing the inflammation on the inflamed hind paws of rabbits. Sweet tamarind showed rapid reduction of inflammation because of the phytochemicals it contains such as alkaloids, flavonoids and flavonols. which are known to reduce inflammation and oxidative stress, promote healing and repair skin damage. Alkaloids also occur in the leaves, pulp and bark of pure extract function as photoprolectants, modulate antibacterial effects and reduction of inflammation.

Regarding with the intensity of the redness as rated by the evaluators, the results showed that the treatments showed no significant effect on the hind paws of rabbits and they also have no significant difference at different time intervals, these means that the ratings of the evaluators are all the same regarding their perceptions in analyzing the redness

TABLE VI

REDNESS RATING OF THE INFLAMED HIND PAWS OF RABBITS TREATED WITH DIFFERENT TAMARIND EXTRACT BASED OINTMENT

\begin{tabular}{|c|c|c|c|c|c|c|c|}
\hline Treatments & \multicolumn{7}{|c|}{ Time/Hour } \\
\hline & Initial & $1^{\text {st a }}$ & $2^{\text {nd a }}$ & $3^{\text {rd a }}$ & $4^{\text {th a }}$ & $5^{\text {th a }}$ & 6 $^{\text {th a }}$ \\
\hline Leaves & 1 & 2 & 2 & 2 & 2 & 2 & $2^{\text {a }}$ \\
\hline Pulp & 2 & 3 & 3 & 2 & 2 & 2 & $2^{\text {a }}$ \\
\hline Bark & 1 & 3 & 3 & 3 & 2 & 2 & $2^{\text {a }}$ \\
\hline Vandol & 1 & 2 & 2 & 2 & 2 & 2 & $1^{\text {TM }}$ \\
\hline Petroleum & 1 & 3 & 3 & 2 & 2 & 2 & $2^{\text {a }}$ \\
\hline
\end{tabular}

* Mean of the same letter shows no significant difference

1- Normal Redness 2- Slight Redness 3- Medium Redness 4- Extreme Redness

TABLE VII

Average PERCENTAge of Wound REDUCTION OF MiCE AFTER 7 Days OF TREATMENT USING TAMARIND OINTMENT

\begin{tabular}{|c|c|c|c|}
\hline $\begin{array}{c}\text { Respondent } \\
\text { Mice }\end{array}$ & $\begin{array}{c}\text { Initial wound size } \\
\text { Average }\left(\mathrm{cm}^{2}\right)\end{array}$ & $\begin{array}{c}\text { Final size } \\
\left(\mathrm{cm}^{2}\right)\end{array}$ & $\begin{array}{c}\text { Wound } \\
\text { Reduction Size } \\
(\%) \text { Reduction }\end{array}$ \\
\hline $\mathrm{T}+$ & 1 & .1 & $90 \%$ \\
\hline $\mathrm{T} 1$ & 1 & .11 & $89 \%$ \\
\hline
\end{tabular}

\section{G. Wound healing effect of tamarind bark ointment and commercial ointment at different time intervals}

The tables indicate that the wound closure in Tamarind Bark Ointment is slightly higher than the Commercial Antibacterial Ointment, this maybe explained by the biologically active components of tamarind such as its flavonoids, alkaloids and tannins which are known to reduce inflammation and oxidative stress, promote healing and repair skin damage.

\section{H. Characterization of Tamarind and Sweet Sorghum Spa} Salt

Table 8 presents the acceptability test of Tamarind Spa Salt and Sweet Sorghum Juggery Spa Salt. Results indicates that both Tamarind spa salts and Sweet Sorghum spa salts are highly acceptable and effective in their relaxing effects.

TABLE VIII

CHARACTERIZATION OF TAMARIND AND SWEET SORGHUM SPA SALT

\begin{tabular}{|l|c|c|}
\hline & $\begin{array}{c}\text { T1 } \\
\text { (tamarind pulp) }\end{array}$ & $\begin{array}{c}\text { T2 } \\
\text { Sweet sorghum } \\
\text { (juggery) }\end{array}$ \\
\hline Odor & 3.83 & 3.70 \\
\hline Texture & 3.60 & 3.83 \\
\hline Color & 3.40 & 3.67 \\
\hline Appearance & 3.20 & 3.83 \\
\hline $\begin{array}{l}\text { Effectiveness (Skin } \\
\text { Smoothening Effect) }\end{array}$ & 3.40 & 3.67 \\
\hline Relaxing property & 3.40 & 3.67 \\
\hline
\end{tabular}

I. Mean Sensory Evaluation of the Physical Attributes of Tamarind and Sweet Sorghum Liniment as Perceived by Liniment Users and Experts

Table 9 presents the mean sensory evaluation of the physical attributes of Tamarind Liniment and Sweet Sorghum Liniment . Results indicates that both liniments are comparable with the commercial liniment in terms of their texture, appearance and effectiveness .

TABLE IX

Mean Sensory Evaluation of THE Physical AtTRibutes of TAMARIND AND SWEET SORGHUM LINIMENT AS PERCEIVED BY LINIMENT USERS AND EXPERTS

\begin{tabular}{|c|c|c|c|c|c|c|c|}
\hline 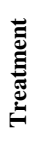 & 产 & $\grave{o}$ & 苞 & $\begin{array}{l}\stackrel{\vec{n}}{0} \\
\stackrel{0}{0} \\
\stackrel{2}{>}\end{array}$ & 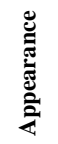 & 总 & 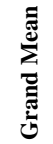 \\
\hline $\mathbf{T}+$ & 4.00 & 3.9 & 4.00 & 3.9 & 4.00 & 4.00 & 3.97 \\
\hline T1 & 3.9 & 3.95 & 4.00 & 3.9 & 4.00 & 4.00 & 3.96 \\
\hline T2 & 3.9 & 3.95 & 4.00 & 4.00 & 4.00 & 4.00 & 3.98 \\
\hline
\end{tabular}

$\mathrm{T}+$ Commercial Liniment

T 1 Tamarind Liniment

T2 Sweet Sorghum Liniment

\section{J. Mean Sensory Evaluation of the Physical Properties of Tamarind and Sweet Sorghum Shower Gels}

Table 10 shows the mean sensory evaluation or acceptability of the Tamarind and Sweet Sorghum Shower Gels. Results indicates the comparative acceptability of the Tamarind and Sweet Sorghum Shower Gel with the Commercial Shower gel in terms of their color, odor, texture, viscosity, appearance and effectiveness. The grand mean of the sensory evaluation of the tamarind shower gel, sweet sorghum shower gel and commercial shower gel showed no significant differences. 
TABLE X

Mean SEnsory Evaluation of THE Physical Properties of TAMARIND AND SWEET SORGHUM SHOWER GELS

\begin{tabular}{|c|c|c|c|c|c|c|c|}
\hline 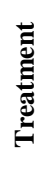 & $\frac{\dot{a}}{\dot{\theta}}$ & $\frac{\grave{o}}{0}$ & 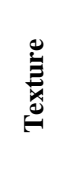 & 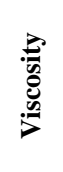 & 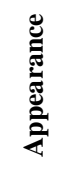 & 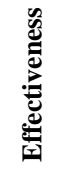 & 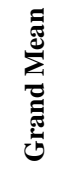 \\
\hline $\mathbf{T}+$ & 4.00 & 4.00 & 4.00 & 4.00 & 4.00 & 4.00 & 4.00 \\
\hline T1 & 4.00 & 4.00 & 4.00 & 4.00 & 4.00 & 4.00 & 4.00 \\
\hline T2 & 3.94 & 3.94 & 4.00 & 4.00 & $3-94$ & 4.00 & 3.97 \\
\hline
\end{tabular}

$\mathrm{T}+$ Commercial Shower Gel

T1 Tamarind Shower Gel

T2 Sweet Sorghum Shower Gel

\section{K. Antibacterial Property of Tamarind Shower Gel and Sweet Sorghum Shower Gel}

Table 11 presents the antibacterial property of Tamarind Shower Gel and Sweet Sorghum Shower Gel. Results indicates that both shower gels possess antibacterial potential against Staphylococcus aurous. However Tamarind Shower Gel has higher zone of inhibition than the Sweet Sorghum Shower Gel.

TABLE XI

ANTIBACTERIAL PROPERTY OF TAMARIND SHOWER GELAND SWEET SORGHUM SHOWER GEL

\begin{tabular}{|c|c|c|c|c|c|}
\hline Treatments & I & II & III & Total & Mean \\
\hline $\mathrm{T}+$ & 0 & 0 & 0 & 0 & 0 \\
\hline Tamarind & $4 \mathrm{~mm}$ & $5 \mathrm{~mm}$ & $4 \mathrm{~mm}$ & $13 \mathrm{~mm}$ & $4.33 \mathrm{~mm}$ \\
\hline Sorghum & $1.67 \mathrm{~mm}$ & $2.00 \mathrm{~mm}$ & $2.00 \mathrm{~mm}$ & $5.67 \mathrm{~mm}$ & $1.89 \mathrm{~mm}$ \\
\hline
\end{tabular}

\section{Economic Potential of Natural Products from Tamarind and Sweet Sorghum}

Production of Selected Non- Food Products from Tamarind and Sweet Sorghum presents the expected initial income in the production of tamarind soap, sweet sorghum soap, tamarind liniment, sweet sorghum liniment, tamarind ointment, tamarind shower gel and sorghum shower gel as calculated based on the gross income minus the cost of production. Products were presented during the exhibits participated in by the University for promotion and sale

TABLE XII

OVERALL COST ANALYSIS OF TAMARIND AND SWEET SORGHUM NON - FOOD PRODUCTS

\begin{tabular}{|c|c|c|c|c|c|c|}
\hline Particular & Soap & Ointment & Spa salt & Liniment & $\begin{array}{c}\text { Shower } \\
\text { Gel }\end{array}$ & $\begin{array}{c}\text { Body } \\
\text { Scrub }\end{array}$ \\
\hline $\begin{array}{c}\text { Est. number of } \\
\text { products }\end{array}$ & 2,160 soap & $150 \mathrm{pcs}$ & $100 \mathrm{pcs}$ & 600 bottles & $\begin{array}{c}1000 \\
\text { bottles }\end{array}$ & $100 \mathrm{pcs}$ \\
\hline $\begin{array}{c}\text { Profit Margin } \\
\text { Ratio }\end{array}$ & $22.49 \%$ & $22.11 \%$ & $21.76 \%$ & $42.67 \%$ & $44.88 \%$ & $21.76 \%$ \\
\hline $\begin{array}{c}\text { Suggested selling } \\
\text { price }\end{array}$ & $20 / \mathrm{pc}$ & $60 / \mathrm{pc}$ & $100 / \mathrm{pc}$ & $60 / \mathrm{pc}$ & $50 / \mathrm{bottle}$ & $100 / \mathrm{pc}$ \\
\hline $\begin{array}{c}\text { Gross income } \\
\text { Material cost }\end{array}$ & $33,200.00$ & 9,000 & 10,000 & 36,000 & 50,000 & 10,000 \\
\hline
\end{tabular}

\begin{tabular}{|c|c|c|c|c|c|c|}
\hline Processing cost & - & - & - & - & - & - \\
\hline Total Cost & 33,484 & 7,010 & 7,824 & 20,640 & 27,560 & 7,824 \\
\hline Net income & 9,716 & 1,990 & 2,176 & 15,360 & 22,440 & 2,176 \\
\hline $\begin{array}{c}\text { Return on } \\
\text { investment (\%) }\end{array}$ & $29.02 \%$ & $28.38 \%$ & $27.81 \%$ & $74.42 \%$ & $81.42 \%$ & $27.81 \%$ \\
\hline $\begin{array}{c}\text { Est. number of } \\
\text { products }\end{array}$ & 2,160 soap & $150 \mathrm{pcs}$ & $100 \mathrm{pcs}$ & 600 bottles & $\begin{array}{c}1000 \\
\text { bottles }\end{array}$ & $100 \mathrm{pcs}$ \\
\hline
\end{tabular}

\section{CONCLUSIONS}

The physical characteristics of Tamarind Soap and Sweet Sorghum Soap were acceptable to the respondents. The chemical properties of the Soap indicates that they are safe and they are comparable with the commercial herbal soap. Both soap showed antibacterial potential against Staphylococcus aurous. Hence, Tamarind Soap and Sweet Sorghum Soap can both be recommended as Germicidal Soap. The Tamarind Leaves Soap and Sweet Sorghum Soap possess Anti - acne and wound healing potential. Tamarind leaves soap is effective against acne regardless of concentration. Tamarind bark ointment possess an antiinflammatory potential particularly for swelling, redness and wounds. Tamarind and Sweet Sorghum Shower Gels, Spa Salts and liniments are acceptable and effective as perceived by the respondents and are comparable with the commercial . Tamarind Shower Gel and Sweet Sorghum Shower Gel possess antibacterial potential against Staphylococcus aurous. Tamarind and Sweet Sorghum Natural Products can promote the Commercialization of Tamarind and Sweet Sorghum.

Dermatological test maybe conducted to further prove the safety and efficacy of the products. Advertisement maybe formed to promote the Natural products from Tamarind and Sweet Sorghum.

\section{ACKNOWLEDGMENT}

The researcher would like to thank its Funding Agency, Pampanga Agricultural College and DA - BAR for without them this research would not be possible. The researcher would like to thank the Office of the Director of Research, Office of the Tamarind Center, Office of the ALIAS Center, Institute of Teacher Education and Institute of Veterinary Medicine (Microbiology Lab) and all of the Students and Natural Products Enthusiasts who served as respondents in this Study.

\section{REFERENCES}

[1] Rummel , D.J. Botanical Beauty Book Compendium of Cosmetic Uses. C \& E Publishing House. Quezon City.2005.

[2] Leonardo, L. Co Common Medicinal Plants of the Cordillera Region (Northern Luzon, Philippines) Rianella Printing Press, Baguio City, Philippines, 2011

[3] Cardenas, L.B. Herbal Medicine. University of the Philippines.Laguna.2007

[4] Ticzon,R.R. Herbs Beauty Aids, Cosmetics \& Hygienics Philippine Style . Philippines.1993

[5] Guevarra , B.Q. A Guidebook to Plant Screening : Phytochemical and Biological Revised Ed. University of Santo Tomas Publishing House. Manila . 2005

[6] Mendoza ,E.E. Chemistry Laboratory Manual .Phoenix Publishing House , Inc. Quezon City . 2004 